Published in final edited form as:

Bull Lat Am Res. 2012 July ; 31(3): 302-319. doi:10.1111/j.1470-9856.2011.00642.x.

\title{
Long Term Influences of Age-Education Transition on the Brazilian Labour Market
}

\author{
ERNESTO FRIEDRICH DE LIMA AMARAL, \\ Universidade Federal de Minas Gerais, Brazil
}

EDUARDO LUIZ GONÇALVES RIOS-NETO, and

Universidade Federal de Minas Gerais, Brazil

JOSEPH E. POTTER

University of Texas at Austin, USA

\begin{abstract}
The objective of this study is to estimate the long term mean earnings of the male Brazilian population, taking into account the ageing process of the population and the increase in educational attainment. Using census data, household sample surveys, as well as population and education projections, estimates indicate that an ageing population and an increase in education will have a 2 percent impact on the annual growth of an average income in Brazil by 2050 . The challenge for the future is to improve the proportion of the Brazilian population with completed college degrees.
\end{abstract}

\section{Keywords}

demographic transition; educational transition; cohort size; economic development; projection of earnings; Brazil

The decline in fertility has been a notable characteristic of Brazil's population in recent decades and has shown a wide variation in time, pace and scale among different states and municipalities (Potter et al., 2010). School attendance has grown substantially from very low levels, but large regional variations still exist (Riani, 2005; Amaral et al., 2007; Rios-Neto, 2009). Demographic dynamics suggest an ageing of the population structure in the coming decades, characterised by increasing participation of older age groups in the working population. Concurrently, educational dynamics indicate an increase in the population's average education. The purpose of this study is to investigate the influence of these demographic and educational transitions on workers' income using data obtained from censuses and household surveys, as well as a theoretical framework determined by previous studies (Easterlin, 1978; Freeman, 1979; Welch, 1979; Berger, 1985). Regional variations in the country's age and education transitions will be used to predict who gains and who loses in the labour market as a result of such changes in its composition. The economic implications of these demographic and educational processes will be felt for more than half of the twenty-first century. The aim of this study, therefore, is to examine scenarios and make projections to simulate the future impact of these transitions on workers' income. The article has five distinct parts: a) a brief discussion of population dynamics and economic 
development; b) an estimation of the impact of the age and education structure on income; c) a formulation of population and education projections; d) a simulation of the future impact of age and education structure on income; and e) concluding remarks.

\section{Population Dynamics and Economic Development Demographic Dividends}

Several studies have found that a decrease in the dependency ratio (decline in proportion of children aged 0-14 and seniors aged 65 or older compared to the proportion of workers between 15 and 64 years of age) caused by the rapid decline in fertility has influenced economic development, especially in countries in East and Southeast Asia (Bloom and Freeman, 1986; Bloom et al., 2000, 2003; Kelley and Schmidt, 2001; Williamson, 2003; Feng and Mason, 2005; Mason, 2005; Bloom and Finlay, 2009). These studies focused on the consequences of changes in population age distribution, rather than the population growth rate. This process, known as the demographic dividend, means that changes in age structure result in fewer resources being allocated for investment in new cohorts. Thus these resources can be used for investment in economic development and family welfare. The greater proportion of people who are of a working age is a temporary effect because this population will age, and the dependency ratio will increase again after a few decades. This temporary decline in the dependency ratio is seen as a window of opportunity for implementing specific public policies to generate economic growth.

The main focus of literature on the first demographic dividend has been on the direct impact of the age structure (decrease in dependency ratio) on economic development (Bloom et al., 2003, 2009, 2011; Bloom and Finlay, 2009). The second demographic dividend shows that population ageing increases the length of retirement time, which enables capital to be accumulated and wealth to be created. This second dividend indicates that the accumulation of wealth and the consequent increase in capital intensity (capital per worker) have direct effects on productivity and economic growth. The first demographic dividend has a temporary impact on the economy. The second demographic dividend allows those benefits to be spread over time, creating sustainable development (Lee et al., 2003; Feng and Mason, 2005; Mason, 2005; Mason and Kinugasa, 2005; Lee and Mason, 2006; Mason and Lee, 2006; Mason et al., 2009).

According to United Nations data (2008), the age distribution of Brazil's population has changed in recent decades. The infant mortality rate (IMR) has declined since 1950 with a subsequent increase in life expectancy at birth $\left(\mathrm{e}_{0}\right)$. The total fertility rate (TFR) has declined since the 1960s. As a result, the youth dependency ratio has been decreasing since the late 1960s and will continue to fall significantly in the coming decades. The elderly dependency ratio has been increasing since 2000 and is estimated to continue growing in the coming years. The combination of young and old age dependency ratios indicates that the dependency ratio will increase by 2030 . However, Brazil is not utilising the economic growth potential, created by the first dividend, and is not creating conditions to generate the second dividend (Turra and Queiroz, 2009; Queiroz and Turra, 2010). Public policy makers are not basing decisions on technical issues and are ignoring the temporary nature of the demographic transition. 


\section{Influence of Age, Experience and Cohort Size on Income}

In addition to these macroeconomic structural aspects, the composition of the Brazilian population between 15 and 64 years of age has, with great regional variation, undergone drastic change in terms of age and education. There is an increase in age and education amongst the working population. The present study seeks to investigate whether these changes have had an effect beyond the estimates based on an analysis of the demographic dividend. In this study, the analysis was restricted to people of working age (15-64 years), in order to estimate the effect of age and education changes in the workforce on the income of these workers, both in previous years and in the coming decades.

The study of changes in age structure and income distribution began with an analysis of the influence of the baby boom on the job market in the US. To go beyond the relationship between the dependency ratio and economic development, a theoretical-methodological framework of this American demographic phenomenon can be employed to investigate Brazil's situation. There is a vast literature on changes in the age and education structure in the US: a) cohorts born during the baby boom and with higher education entered the US labour market in the 1970s; b) the number of people with 5-8 years of schooling and 1-3 years of secondary study decreased considerably; and c) the number of people who completed secondary education and at least some higher education has grown significantly. Studies on the baby boom and the labour market suggest that larger cohorts of workers cause a reduction in income and that this effect is greater for more educated groups (Easterlin, 1978; Freeman, 1979; Welch, 1979; Berger, 1985). Sapozhnikov and Triest (2007) indicated that those born during the baby boom would continue to affect the income structure even after they reach retirement.

These analyses illustrate that the theoretical framework of supply and demand for labour is important when studying the effect of population changes in the labour market. An increase in the supply of skilled labour would lead to a decline in the reward for skills (skill premium). This premium is defined as the ratio between the income of highly skilled workers and that of less skilled workers. However, this skill premium grew alongside increased availability of more educated workers in the US (Katz and Murphy, 1992; Autor et al., 1998; Katz and Autor, 1999), which explains the trends in relative incomes between 1967 and 1987. This occurred because growth in the supply of these workers coincided with an increased demand for more qualified individuals in the labour market.

The influence of demographic and educational changes on various aspects of the labour market may also be ascertained using data from different countries (Korenman and Neumark, 2000; Shimer, 2001; Skans, 2005; Biagi and Lucifora, 2008; Brunello, 2010). Analysing the growth of cohorts of young people in the US, Shimer (2001) found that there was a decline in the rate of unemployment and an increase in workforce participation. This result is inconsistent with theories on the impact of cohort size on the labour market (Korenman and Neumark, 2000; Skans, 2005; Biagi and Lucifora, 2008; Brunello, 2010). According to American panel data, the different results may be explained by the use of time fixed effects (Shimer, 2001). These fixed effects control for labour demand factors, reducing variations in the data during the process of estimating the impact of the labour supply (caused by demographic and educational changes) on the labour market. 
Studies have determined several reasons for the increase in population with higher education, since the 1970s, in American cities that already had higher levels of education compared to other locations (Moretti, 2004; Berry and Glaeser, 2005). By controlling for unobserved labour demand factors (instrumental variables) specific to each American city, Moretti (2004) found that positive effects on income are greater for groups with less education.

Could changes in the Brazilian age and education structures also have influenced income in the labour market? What age and education groups were the most affected? How might these effects be simulated in the long term? The next section describes the methodology for estimating the impact of changes in age and education structure on workers' income (Amaral et al., 2007). This proposal was based on studies that considered the impact of cohort size on the labour market (Freeman, 1979; Welch, 1979; Berger, 1985; Sapozhnikov and Triest, 2007). Area and time fixed effects removed much of the data variation (Shimer, 2001) so that the effect of demographic and educational changes on workers' income could be accurately estimated. These models were constructed by taking into account the demographic and educational realities of Brazil (Paes de Barros et al., 2002; Riani, 2005; Rios-Neto, 2009; Potter et al., 2010), and available census data.

\section{Impact of Age Structure and Education on the Income of Workers}

The estimation of an income equation is central in assessing the impact of an ageing population and an increase in education on an average income. This analysis seeks to establish whether changes in age and education structures would have influenced income in Brazil. Before estimating the models, it is important to evaluate the distribution of the male population and the average income of these individuals by year and age-education group in the country (Table 1). In general, the population figures indicate that the proportion of men with 0-4 years of education decreased between 1970 and 2000. For example, the proportion between 15 and 24 years of age with $0-4$ years of education fell considerably from 28.19 percent in 1970 to 9.04 percent in 2000. In addition, the proportion of those with 5-8 years of education or at least 9 years of education increased during the period. The largest increases in the proportions of men with at least 9 years of schooling were for those in the 15-24 year age group, from 2.74 percent in 1970 to 10.24 percent in 2000, and for those in the 35-49 year age group, from 1.59 percent in 1970 to 8.46 percent in 2000.

Table 1 also shows the real average income for the primary occupation by year and ageeducation group. Analysis of this data must take into account that the levels and patterns of average income may be influenced by the wide variation among individuals within each age and education group. With this in mind, these average incomes are still a useful tool for examining the differences among the groups over the years. As expected, incomes are higher for older and more educated men. The increase in average income between 1970 and 1980 is explained by the economic growth that occurred in Brazil in the 1970s. Due to the economic recession in the 1980s, average incomes fell in 1991. From 1991 to 2000, incomes increased for less educated men in all age groups and for those with higher education in the older age group. In other groups, incomes decreased from 1991 to 2000, resulting in smaller disparities between education groups and across all age groups in 2000 . 
In order to build models to evaluate the impact of age and education transitions in the labour market, one must take into account that, as in other developing countries, Brazilian transitions have a significant degree of geographical heterogeneity. In other words, the decline in fertility has varied over time and among states and municipalities (Potter et al., 2010). In addition, education in the country has increased considerably, but it remains at a low average level, and there is great variation among different locations in Brazil (Riani, 2005; Amaral et al., 2007; Rios-Neto, 2009). The goal of this study was to use these geographical and temporal variations to analyse the impact of demographic and educational changes in the labour market of Brazilian micro-regions (groups of municipalities).

Because of the wide variation in Brazil's income distribution, the dependent variable for the models was set as the logarithm of real average income in the primary occupation by year, micro-region and age-education group (Amaral et al., 2007). Only men were included in the estimated models. The individuals were divided into four age groups (15-24, 25-34, 35-49 and 50-64 years) and three educational groups (0-4, 5-8 and 9+ years of study), resulting in twelve age-education groups. Microdata from the Brazilian demographic censuses of 1970, 1980, 1991 and 2000 were used (IBGE, 2010a, 2010b, 2010c, 2010d). The geographic compatibility of the Brazilian micro-regions among the various censuses, a total of 502 areas, made this longitudinal study possible.

First, the standard labour market model was estimated to consider only the direct impact of education and age on income (through dichotomous variables of age-education groups). The model ignores the role of the relative size of each of the twelve age-education groups, the element that identifies the labour demand curve. This standard model is called the Mincerian equation because it estimates income using information on age and education, as suggested by Mincer $(1958,1974)$. The results indicate that, within the same age group, the income of the male population increased as the level of education increased. Similarly, within an education group, as age increased, income also increased. The results confirm what is expected theoretically in terms of return rate, both for education and for age (as a proxy for experience).

By including information on the male population's age and education structures (relative proportions of the twelve age-education groups), it is possible to estimate the substitution model of demand for labour, in contrast to the Mincerian model. As shown by the Mincerian model, dichotomous age-education variables indicate that within each age category, income is higher for those with more education. Similarly, within each education group, income increases with age. Furthermore, as expected by the theory of labour demand, the proportion of each age-education group usually has a negative effect on income (Figures 1 and 2). The negative impact of the proportions tends to be more pronounced when the education level of the group is higher. However, the coefficient is less negative over time, with the exception of the lowest education group. The impact of the proportions on income becomes positive in some older age groups with high levels of education (9 years or more) in 2000. In general, changes caused by education in the labour supply had a smaller impact on relative wages in 2000 compared to 1970. 
These models allow the estimation of the effects of change in age and education structures on the income of the Brazilian male labour force. The results suggest that changes in workforce composition are influential and that such analysis can be useful to economic development studies. This study provided insight into previous decades. An estimate is still required for how these effects will develop over the long term. To simulate the impact of changes on income composition, it is necessary to first project the Brazilian population by age and education groups for the years 2005, 2025 and 2050. This exercise is performed in the next section.

\section{Population and Education Projections}

\section{Population Projection}

The process of change in the demographic composition of the Brazilian population will occur throughout the majority of the twenty-first century. It is important to obtain population projections to serve as an input for simulations of the impact of age structure on the labour market. The country has been through a demographic transition marked by a decline in the mortality rate and an increase in life expectancy at birth since the second half of the 1940s. There has also been a significant drop in total fertility rate (TFR), defined as the number of live births during the reproductive period of a hypothetical woman. The TFR has changed from almost 6 children per woman in 1970 to 4.4 children in 1980, falling to 2.3 children per woman in 2000. During the first decade of this millennium (2001-2006), the fertility rate was 1.8 children per woman, which is below the replacement level of 2.1 children per woman. When fertility is at this level for a sufficiently long period, population growth is zero. Several European countries have fertility rates below this level.

Figure 3 clearly shows the impact of the demographic transition on the Brazilian age structure of the male working age population. There is increased participation of the oldest group and reduced participation of the youngest. The projection of the Instituto Brasileiro de Geografia e Estatística (Brazilian Institute of Geography and Statistics IBGE), provides the figures for the working age population, in order to estimate the average income in 2005 , 2025 and 2050.

\section{Education Projection}

In order to estimate the impact of age and education structures on income in 2005, 2025 and 2050 , it is also necessary to project the future education levels of the overall Brazilian population. It is possible to verify the growth trends of the various educational groups in recent decades based on data from the Pesquisa Nacional por Amostra de Domicílios (National Household Sample Surveys [PNAD], 1979, 1981, 1985, 1990, 1995, 1999, 2001 and 2005 (IBGE, 2010e, 2010f, 2010g). The education variable was categorised into three groups ( $0-4,5-8$ and $9+$ years of study). Population growth trends per each educational group are analysed with the age-period-cohort (APC) model (Oliveira, 2005). This method was selected, because it considers the separate effects of these three components (age, period and cohort) on education, facilitating the simulation of future scenarios of education patterns. This method requires equally sized age and period intervals, allowing us to verify the educational trends by five-year age groups over periods of five years. With a total of ten 
age groups $(15-19,20-24,25-29,30-34,35-39,40-44,45-49,50-54,55-59$ and 60-64) and six distinct periods (1980, 1985, 1990, 1995, 2000 and 2005), fifteen cohorts are generated (1916-1920-1921-1925-1926-1930-1931-1935-1936-1940-1941-1945-19461950-1951-1955-1956-1960-1961-1965-1966-1970-1971-1975-1976-1980-1981-1985 and 1986-1990). Information for 1980 was obtained using data from 1979 and 1981; for 2000, data from 1999 and 2001 were used.

The analysis of the pure effects of age, period and cohort on the population, broken down by educational groups, was performed with a generalised multinomial logit model. The dependent variable was education, categorised into the three groups listed above. Age, period and cohort data were used as independent categorical variables. The variable with the frequency of people in each age-period-cohort-education category was used to indicate each group's weight. This procedure took into account information from individual sampling weights, available in each one of the PNADs.

To better understand the trend of the structure of the male population by education, age, period and cohort groups, two regression models were estimated, changing only the reference categories. To demonstrate how this trend will develop over the coming years and decades, the model that takes into account the 15-19 year age group as the reference is more instructive than the one using the 60-64 year age group as the reference. The results are similar, and only the first model estimates are shown in Figure 4.

To obtain the pure effect of age, Figure 4 illustrates that men in age groups 20-24, 25-29 and 30-34 have higher odds ratios (relative to the 15-19 year age group) of belonging to the $9+$ years of education group (compared to the group of 0-4 years of study). The group with 5-8 years of education has lower odds ratios (compared to the reference group with 0-4 years of education) at all ages (relative to the 15-19 age group). As age increases, the odds ratio of belonging to the groups with 5-8 and 9+ years of education (compared to 0-4 years of education) tends to decrease, which is an indication of a higher level of education for younger men.

The pure effect of each period on male population trends, disaggregated by education group, can also be seen. In more recent periods, the odds ratios of the male population increased in the groups that have 5-8 and 9+ years of education, compared to those with 0-4 years of education. In 2000, the increase in the odds ratio becomes stronger for the group with 9+ years of education, while the positive slope decreases for the group with 5-8 years of education.

Finally, the pure effect of each cohort on trends of the male population by education can also be seen. There is a gradual decrease in the education of the younger cohorts up to those born between 1971 and 1975. For the cohort born from 1976 to 1980 onwards, a significant increase in the rate of education of the male population can be observed. The group with 9+ years of study has an even stronger growth in the two youngest cohorts (1981-1985 and 1986-1990), compared to the group with 5-8 years of education.

The generalised multinomial logit model, specifying age, period and cohort, was used to observe education trends of a birth cohort across various age groups through time. The 
model fit can be considered satisfying, since the estimated trends on education groups follow those of the observed data. The next step is to construct scenarios of how the educational structure will behave in the coming decades. In other words, it is necessary to predict how the regression coefficients will behave in the future, based on various possible configurations of the educational dynamic over the long term. The estimated APC model was used to outline three scenarios. In scenario A, there is an ageing population, but the education levels of 1980 are kept constant, which is not a realistic projection. Scenario B predicts a future variation in period and cohort coefficients that follow the historical trend of the entire database model (1980-2005). Scenario C predicts a future variation extrapolated from the growth rate of the period and cohort coefficients in the last three years of the series (1995, 2000 and 2005), which is a more optimistic projection of education improvement.

\section{Integration of Population and Education Projections}

The combination of the IBGE population projection and the education projection generated by the APC model will be used to estimate the impact of age and education structures on incomes in the long term. More specifically, the projected populations by age and education groups will be used to estimate future impacts of demographic and educational changes on Brazil's income structure. Table 2 shows the interaction of population projection (Figure 3) with the education projection of scenario C (based on Figure 4), using the age-education groups necessary to apply the regression models. The analysis of Table 2 shows the ongoing population ageing in Brazil. Over time, there is a decrease in the percentage of groups with low education and an increase in the more educated groups. In other words, population ageing and the increase in education interact in the projection. This result is important because age (an indicator of labour market experience) and education (an indicator of investment in human capital) positively affect income.

More specifically, the projection results are significant because they estimate that by 2025 , nearly all of the people in the younger generations will have 9+ years of education. In 2050, the education groups with 0-4 and 5-8 years of study will represent less than 2 percent of the population combined (Table 2). This effect might be overestimated due to the extrapolation used in our method. However, these estimates were based on trends from recent years. Although the projection's result is based on the optimistic assumption that Brazilian education will ultimately improve in the long term (scenario $\mathrm{C}$ ), there are reasons for concern. In another study (Rios-Neto, 2009), high school education (incomplete and complete, i.e., 9-11 years of study) and college education (incomplete and complete, i.e., 12 years of study or more) were separated into projections for four education groups $(0-4,5-8$, 9-11 and 12+ years of schooling). Results indicated that much of the growth shown in Table 2 is concentrated on high school and not on college education. Therefore, increasing the proportion of the Brazilian population who complete college education is a key challenge for the future economic dynamic in the country. 


\section{Simulations of the Future Impact of Age Structure and Education on Income}

Given the estimated coefficients of the models from Amaral et al. (2007), as well as population projections by age-education groups for 2005, 2025 and 2050 (Table 2), it is possible to simulate future income, based on the Mincerian and substitution models. Instead of using the estimated coefficients for the year 2000, the annual variation of the coefficients between 1991 and 2000 is used to extrapolate all the coefficients for 2005. These coefficients projected for 2005 are used to calculate the expected income based on the Mincerian and substitution models for three years: 2005, 2025 and 2050. The substitution model also takes into account the projected distribution of the male population by the twelve age-education groups. As in the education projection, three scenarios are considered: i) scenario A considers the ageing of the population, but maintains the same education distribution as in 1980, which is unlikely to occur; ii) scenario B also takes into account population ageing, and education is projected in accordance with the trends of all cohorts and all periods (1980-2005); and iii) scenario C considers population ageing, as well as the trend of education growth for the last three points of cohort and period (1995, 2000 and 2005). Because the latter scenario is more optimistic, only its results are shown here, despite having estimated incomes similar to those in scenario B.

The average earnings expected in 2005, 2025 and 2050 were estimated using the income from each of the twelve age-education groups, obtained via the population and education projections, as well as the impact of the relative participation of each group. The results of scenario $\mathrm{C}$ indicate that the average incomes are higher in the Mincerian model in 2005 (570.14 Brazilian Reais) and 2025 (875.01 Brazilian Reais) when compared to the substitution model, with values of 509.54 and 860.55 Brazilian Reais, respectively. This is a coherent result because the negative effect of age-education group size on income is included only in the substitution model. However, from the point of view of the expected annual income growth rate, returns are lower in the Mincerian model (2.1 percent) than in the substitution model (2.6 percent) in the period from 2005 to 2025. In 2050, the absolute value of an average income is lower in the Mincerian model (1192.55 Brazilian Reais), compared to the substitution model (1485.04 Brazilian Reais). As a result, the expected annual growth rate of income between 2025 and 2050 is lower in the Mincerian model (1.2 percent) than in the substitution model (2.2 percent).

The distribution of male population by age-education group in 2000 (Table 1), as well as in 2025 and 2050 (Table 2) was used to estimate the average earnings for each age-education group in scenario C. For this exercise, the 2000 coefficients were used (Amaral et al., 2007), i.e., the extrapolation of the 2005 coefficients was not implemented. Figure 5 illustrates the earnings estimated by the Mincerian model only for 2000, because this model does not capture changes in the age-education structure of the population. The substitution model allows earnings to be estimated for 2000, as well as to be simulated for 2025 and 2050, because this model includes the proportions of the male population by age-education group. In addition, Figure 5 illustrates income estimated by the substitution model relative to income estimated by the Mincerian model. The first graph of Figure 5 shows that average 
earnings are greater in 2000 in the Mincerian model estimates, when compared to the substitution model, because the latter includes the negative impact of coefficients of cohort size in the age-education groups. For all groups with 5-8 and 9+ years of education, the average incomes estimated with the substitution model are more than 10 percent lower than those estimated by the Mincerian model in 2000 (second graph of Figure 5).

Regarding future trends, growth relating to the education of the adult population results in lower incomes in 2025 and 2050 in the substitution model, compared to the Mincerian model, as shown in the second graph in Figure 5. For example, this occurs for men with 9+ years of education, aged 15-49 years, as well as for those with 5-8 years of education, aged 50-64 years. Groups with declining relative importance over time have higher incomes in 2025 and 2050 in the substitution model, compared to the Mincerian model, especially those with 5-8 years of education (15-24 and 25-34 years old), and those with 0-4 years of education (35-49 and 50-64 years old).

The biggest difference between the estimates of the two models is for the older group (5064 years old), with higher levels of education (9+ years of study). By considering the size of the age-education group (substitution model), the earnings of this group are 21 percent higher in 2050, compared to estimates of the Mincerian model. The positive impact on income verified in the substitution model could have important future results for this group, which represents only 2.84 percent of the male population in the labour force in 2000 (Table 1), and will increase to almost a third of this population by 2050 (Table 2).

It is important to stress that this analysis is limited to the coefficients estimated for 2000. For example, the positive coefficient for the size of the 50-64 age group with 9+ years of schooling in 2000 (substitution model) was applied to the projected population of this group in 2050 (30.35 percent from Table 2). This is only a simulation of the future impact of demographic and educational dynamics on workers' incomes. It is expected that the coefficients estimated by the substitution model will fluctuate in the coming years due to changes in age-education composition.

The results emphasise the importance of adding information on demographic and educational changes to models that estimate workers' earnings. In Brazil's immediate future, the interaction of population ageing and improvement in education of the working age population on the economy (especially with the demand for labour) will result in significant effects on income by age-education groups. Population and education changes will have significant impacts on earnings, with some groups becoming relatively smaller and others expanding. Taking into account that this simulation does not incorporate technological progress and shifts in the demand curve, it can be inferred that demographic and educational dynamics will determine a productivity increase greater than that estimated by our models, and in this respect, the role of education is crucial.

\section{Final Considerations}

This article analysed the results of an unprecedented simulation exercise incorporating both labour supply (demographic and educational transitions) and labour demand (time and area fixed effects). The results are based on long term projections of both population and 
education in Brazil. It is important to note that these projections are only indicative of future trends, and they should not be considered to have high predictive power. Nonetheless, the results show that the combination of an ageing population with improving education has a profound effect in terms of an increase in expected average earnings.

Several points should be raised by way of conclusion. First, it should be noted that the fall in fertility is reducing the concentration at the labour market's entry point (15-24 age group). At the same time, larger cohorts are passing through towards higher age segments, and this also affects the increase in average income. In the case of the substitution model, the pure effect of an ageing population causes an increase of almost 1 percent in average income. It is possible to conclude that an infinitely elastic supply of labour is an outdated situation.

The incorporation of the education projection indicates that Brazil will eventually complete its education revolution in the long term. This will occur, at least in terms of quantity, with the vast majority of the population having $9+$ years of education. While this is excellent news, other exercises show that this increase is concentrated in high school education (9-11 years of study) and not in college education (12+ years of study) (Rios-Neto, 2009). If the country really wants to revolutionise the structure of income and technological progress, the great challenge for the future is to increase the proportion of the Brazilian population who complete college education. Despite this caution, the simulations demonstrate that the interaction of an ageing population with the expected improvement in education, leads to an annual increase in average earnings of more than 2 percent.

Finally, it should be noted that the simulation developed here incorporates labour demand. The substitution effect in each age-education group causes an increase in average earnings, mainly due to the role of the older and more educated segment, which has been increasing over time. This result would be even greater if the last education group was separated into high school and college education, thus forming four education groups. Previous studies suggest that much of the skill premium is concentrated on the college education segment. The same argument can be made in reference to the role of technological progress. The estimated labour demand presented here takes into account the temporal effect of interactions, but does not incorporate a formula that considers the role of long term technological progress, due to the unavailability of data. If this technological progress was incorporated, especially to control for skill bias, the increase in estimated average earnings would likely be even greater.

\section{Acknowledgments}

This research received support from the Brazilian Association of Population Studies (Associação Brasileira de Estudos Populacionais, ABEP) and the Brazilian Institute of Applied Economic Research (Instituto de Pesquisa Econômica Aplicada, IPEA), through a research scholarship on Demographic Dynamics and Brazilian Development in the Long Term (Dinâmica Demográfica e o Desenvolvimento Brasileiro de Longo Prazo, ABEP/ IPEA, 001/2009). We are grateful to A. Reams for the final editing of this manuscript.

\section{References}

Amaral, EFL.; Hamermesh, DS.; Potter, JE.; Rios-Neto, ELG. Demographic Change and the Structure of Wages: A Demand-Theoretic Analysis for Brazil. NBER; New York: 2007. NBER Working Paper Series 13533 
Autor D, Katz L, Krueger A. Computing Inequality: Have Computers Changed the Labor Market? Quarterly Journal of Economics. 1998; 93:1169-1214.

Berger M. Journal of Political Economy. The Effect of Cohort Size on Earnings Growth: A Reexamination of the Evidence. 1985; 93(3):561-573.

Berry, C.; Glaeser, EL. The Divergence of Human Capital Levels Across Cities. Harvard Institute of Economic Research; Cambridge, MA: 2005. Discussion Paper 2091

Biagi F, Lucifora C. Demographic and Education Effects on Unemployment in Europe. Labour Economics. 2008; 15:1076-1101.

Bloom, DE.; Canning, D.; Fink, G. Implications of Population aging for Economic Growth. Harvard School of Public Health; Boston: 2011. Working Paper 64. Program on the Global Demography of Aging

Bloom DE, Canning D, Fink G, Finlay JE. Fertility, Female Labor Force Participation, and the Demographic Dividend. Journal of Economic Growth. 2009; 14:79-101.

Bloom DE, Canning D, Malaney PN. Population Dynamics and Economic Growth in Asia. Population and Development Review. 2000; 26(Suppl):257-290.

Bloom, DE.; Canning, D.; Sevilla, J. The Demographic Dividend: A New Perspective on the Economic Consequences of Population Change. RAND; Santa Monica: 2003.

Bloom DE, Finlay JE. Demographic Change and Economic Growth in Asia. Asian Economic Policy Review. 2009; 4:45-64.

Bloom DE, Freeman RB. The Effects of Rapid Population Growth on Labor Supply and Employment in Developing Countries. Population and Development Review. 1986; 12(3):381-414.

Brunello G. The Effects of Cohort Size on European Earnings. Journal of Population Economics. 2010; 23:273-290.

Corseuil, CH.; Foguel, MN. Uma Sugestão de Deflatores para Rendas Obtidas a Partir de Algumas Pesquisas Domiciliares do IBGE. Brazilian Institute of Applied Economic Research (IPEA); Rio de Janeiro: 2002. Working Paper 897

Easterlin RA. What Will 1984 Be Like? Socioeconomic Implications of Recent Twists in Age Structure. Demography. 1978; 15(4):397-432. [PubMed: 738471]

Feng, W.; Mason, A. Demographic Dividend and Prospects for Economic Development in China. Paper Presented at the United Nations Expert Group Meeting on Social and Economic Implications of Chaning Population Age Structures; Mexico City. 31 August to 2 September; 2005.

Freeman RB. The Effect of Demographic Factors on Age-Earnings Profiles. Journal of Human Resources. 1979; 14(3):289-318.

IBGE (Instituto Brasileiro de Geografia e Estatística). [accessed 30 November 2010] Censo demograficó 1970: microdados da amostra. 2010a. [WWW document]. URL http:// www.ibge.gov.br/lojavirtual

IBGE. [accessed 30 November 2010] Censo Demografico 1980: microdados da amostrá. 2010b. [WWW document]. URL http://www.ibge.gov.br/lojavirtual

IBGE. [accessed 30 November 2010] Censo demográfico 1991: microdados da amostra. 2010c. [WWW document]. URL http://www.ibge.gov.br/lojavirtual

IBGE. [accessed 30 November 2010] Censo demográfico 2000: microdados da amostra. 2010d. [WWW document]. URL http://www.ibge.gov.br/lojavirtual

IBGE. [accessed 30 November 2010] Pesquisa nacional por amostra de domicílios (PNAD) 1976 a 1986: microdados. 2010e. [WWW document]. URL: http://www.ibge.gov.br/lojavirtual

IBGE. [accessed 30 November 2010] Pesquisa nacional por amostra de domicílios (PNAD) 1987 a 1999: microdados. 2010f. [WWW document]. URL: http://www.ibge.gov.br/lojavirtual

IBGE. [accessed 30 November 2010] Pesquisa nacional por amostra de domicílios (PNAD) 2001 a 2009: microdados. 2010g. [WWW document]. URL http://www.ibge.gov.br/lojavirtual

IBGE. [accessed 30 November 2010] Projeção da população do Brasil por sexo e idade: 1980-2050 revisão 2008. 2010h. [WWW document]. URL http://www.ibge.gov.br/home/estatistica/ populacao/projecao_da_populacao/2008/default.shtm 
Katz, LF.; Autor, DH. Changes in the Wage Structure and Earnings Inequality. In: Ashenfelter, O.; Card, D., editors. Handbook of Labor Economics. Vol. 3. North-Holland; Amsterdam: 1999. p. 1463-1555.

Katz LF, Murphy KM. Changes in Relative Wages, 1963-1987: Supply and Demand Factors. Quarterly Journal of Economics. 1992; 107(1):35-78.

Kelley, AC.; Schmidt, RM. Economic and Demographic Change: A Synthesis of Models, Findings, and Perspectives. In: Birdsall, N.; Kelley, AC.; Sinding, SW., editors. Population Matters: Demographic Change, Economic Growth, and Poverty in the Developing World. Oxford University Press; Oxford: 2001. p. 67-105.

Korenman, S.; Neumark, D. Cohort Crowding and Youth Labor Markets: A Cross-Sectional Analysis. In: Blanchflower, D.; Freeman, R., editors. Youth Employment and Joblessness in Advanced Countries. Chicago University Press; Chicago: 2000. p. 57-105.

Lee R, Mason A. What is the Demographic Dividend? Finance and Development. 2006; 43(3) [WWW document]. URL http://www.imf.org/external/pubs/ft/fandd/2006/09/basics.htm.

Lee R, Mason A, Miller T. Saving, Wealth and the Transition from Transfers to Individual Responsibility: The Cases of Taiwan and the United States. Scandinavian Journal of Economics. 2003; 105(3):339-357.

Mason, A. Demographic Transition and Demographic Dividends in Developed and Developing Countries. United Nations (UN/POP/PD/2005/2); 2005.

Mason, A.; Kinugasa, T. East Asian Economic Development: Two Demographic Dividends. EastWest Center; Honolulu: 2005. Working Papers, Economics Series 83

Mason A, Lee R. Reform and Support Systems for the Elderly in Developing Countries: Capturing the Second Demographic Dividend. Genus. 2006; LXII(2):11-35.

Mason, A.; Lee, R.; Tung, AC.; Lai, MS.; Miller, T. Population Ageing and Intergenerational Transfers: Introducing Age into National Accounts. In: Wise, DA., editor. Developments in the Economics of aging. Chicago University Press; Chicago: 2009. p. 89-122.

Mincer J. Investment in Human Capital and Personal Income Distribution. Journal of Political Economy. 1958; 66(4):281-302.

Mincer, J. Schooling, Experience, and Earnings. National Bureau of Economic Research; New York: 1974.

Moretti E. Estimating the Social Return to Higher Education: Evidence from Longitudinal and Repeated Cross-Sectional Data. Journal of Econometrics. 2004; 121:175-212.

Oliveira, EL. Unpublished doctoral dissertation. Federal University of Minas Gerais (UFMG); Brazil: 2005. Transições: Três Aplicações a Partir de Dados das Pesquisas Domiciliares no Brasil.

Paes De Barros, R.; Henriques, R.; Mendonça, R. Pelo fim das décadas perdidas: educação e desenvolvimento sustentado no Brasil. Brazilian Institute of Applied Economic Research (IPEA); Rio de Janeiro: 2002. Working Paper 857

Potter JE, Schmertmann CP, Assunção RM, Cavenaghi SM. Mapping the Timing, Pace, and Scale of the Fertility Transition in Brazil. Population and Development Review. 2010; 36(2):283-307. [PubMed: 20734553]

Queiroz, BL.; Turra, CM. Window of Opportunity: Socioeconomic Consequences of Demographic Changes in Brazil. Paper Presented at the IUSSP Seminar - Demographics and Macroeconomic Performance; Paris. 4-5 June; 2010.

Riani, JLR. Unpublished doctoral dissertation. Federal University of Minas Gerais (UFMG); Brazil: 2005. Determinantes do Resultado Educacional no Brasil: Família, Perfil Escolar dos Municípios e Dividendo Demograficó numa Abordagem Hierarquicá e Espacial.

Rios-Neto, ELG. Will the Second Demographic Transition Be Global? The Case of Latin America. Paper Presented at the XXVI IUSSP International Population Conference; Marrakech. 27 September to 2 October; 2009.

Sapozhnikov, M.; Triest, RK. Population aging, Labor Demand, and the Structure of Wages. Work Opportunities for Older Americans Series. The Center for Retirement Research; Chestnut Hill: 2007. Working Paper 8, CRR WP 2007-14[WWW document]. URL http://www.crr.bc.edu/ images/stories/Working_Papers/wp_2007-14.pdf [accessed 20 October 2011] 
Shimer R. The Impact of Young Workers on the Aggregate Labor Market. Quarterly Journal of Economics. 2001; 116(3):969-1007.

Skans ON. Age Effects in Swedish Local Labor Markets. Economics Letters. 2005; 86:419-426.

Turra CM, Queiroz BL. Antes de que sea demasiado tarde: transicioń demográfica, mano de obra disponible y problemas de la seguridad social en el Brasil. Notas de Población. 2009; 86:141-165.

United Nations. World Urbanization Prospects: The 2007 Revision Population Database. United Nations Population Division; New York: 2008. [WWW document]. URL http://esa.un.org/unup [accessed 30 November 2010]

Welch F. Effects of Cohort Size on Earnings: The Baby Boom Babies' Financial Bust. Journal of Political Economy. 1979; 87(5):S65-S97.

Williamson, JG. Demographic Change, Economic Growth, and Inequality. In: Birdsall, N.; Kelley, AC.; Sinding, SW., editors. Population Matters. Oxford University Press; Oxford: 2003. p. 106-136. 
15-24 years;

0-4 years of schooling

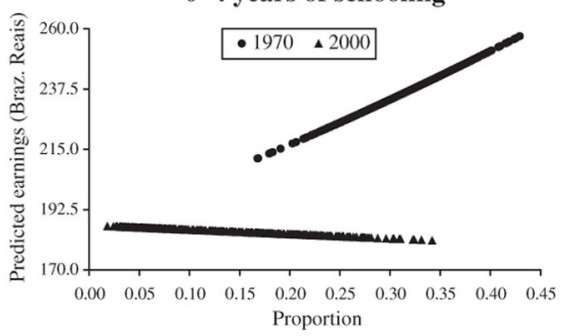

15-24 years;

5-8 years of schooling

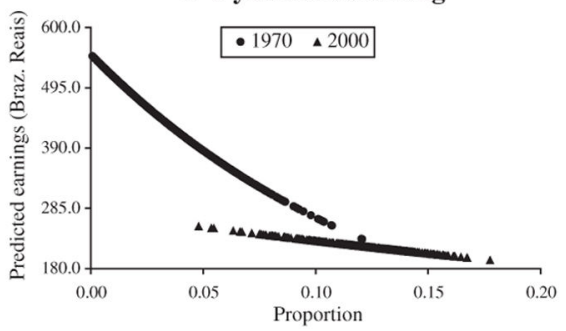

15-24 years;

9+ years of schooling

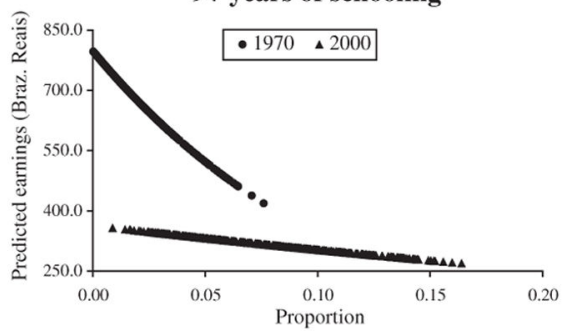

25-34 years;

0-4 years of schooling

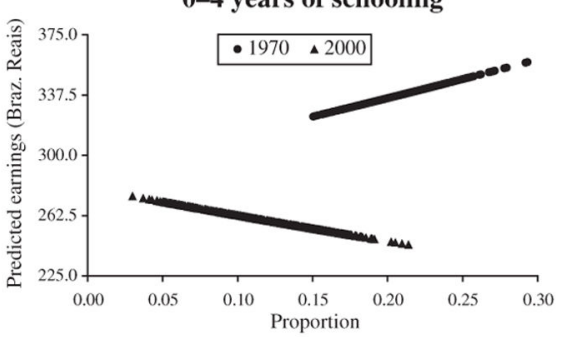

25-34 years;

5-8 years of schooling

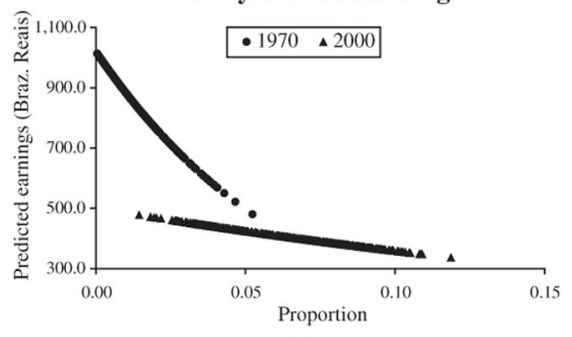

25-34 years;

9+ years of schooling

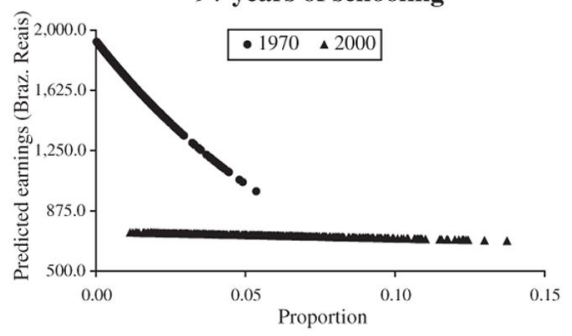

Figure 1.

Predicted Mean Real Monthly Earnings from Primary Occupation ${ }^{\mathrm{a}}$ by Proportion of the Male Population in Age-Education Groups 15-24 years and 25-34 years, 1970 and 2000. Source: IBGE (2010a, 2010b, 2010c, 2010d).

aNominal income was converted to base 1 in January 2002, taking into account changes in currency and inflation (Corseuil and Foguel, 2002). These are estimates from the substitution model. 

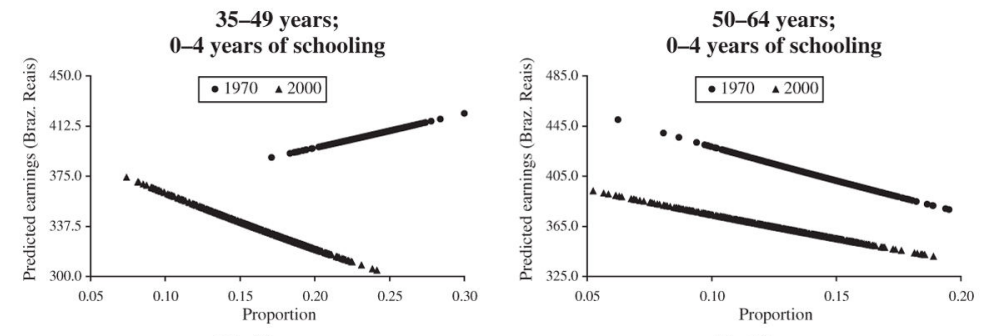

35-49 years;

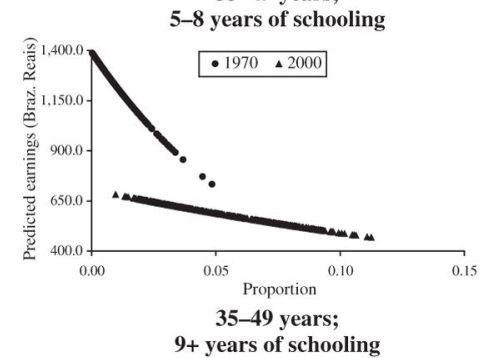

50-64 years;

$50-64$ years;
$5-8$ years of schooling
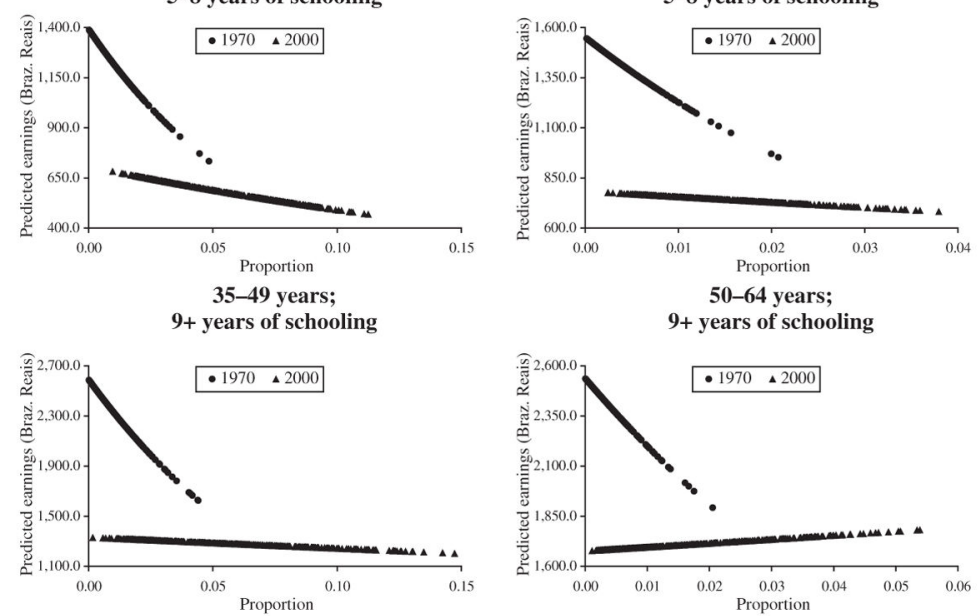

Figure 2.

Predicted Mean Real Monthly Earnings from Primary Occupation ${ }^{\mathrm{a}}$ by Proportion of the Male Population in Age-Education Groups 35-49 years and 50-64 years, 1970 and 2000. Source: IBGE (2010a, 2010b, 2010c, 2010d).

aNominal income was converted to base 1 in January 2002, taking into account changes in currency and inflation (Corseuil and Foguel, 2002). These are estimates from the substitution model. 

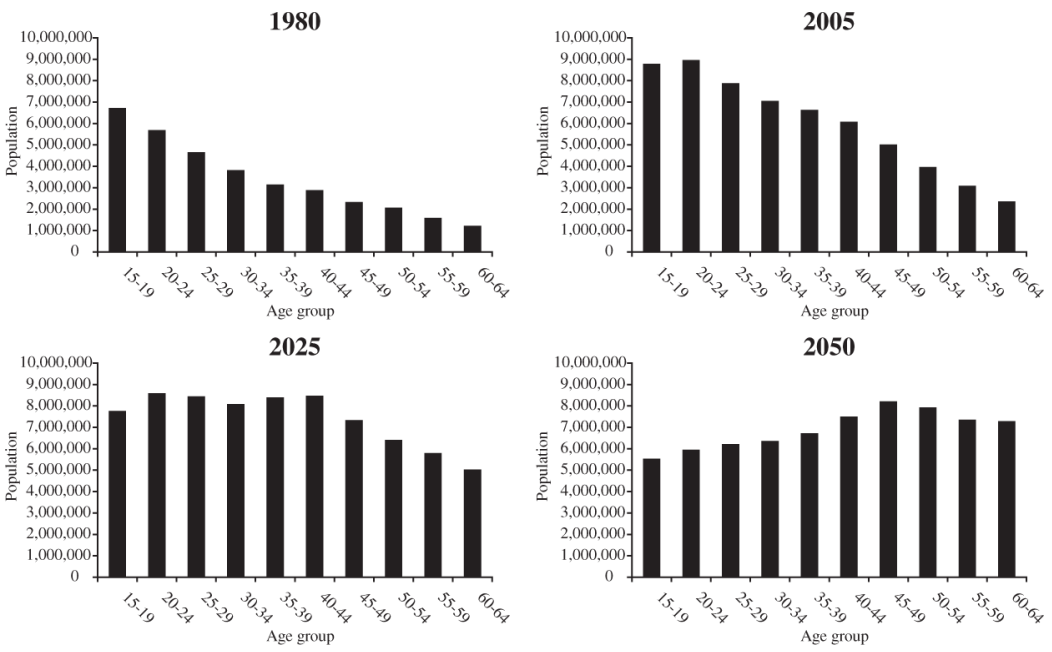

Figure 3.

Distribution of the Projected Male Working-Age Population by Age Group, Brazil, 19802050.

Source: IBGE (2010h), Brazilian Institute of Geography and Statistics (IBGE). 

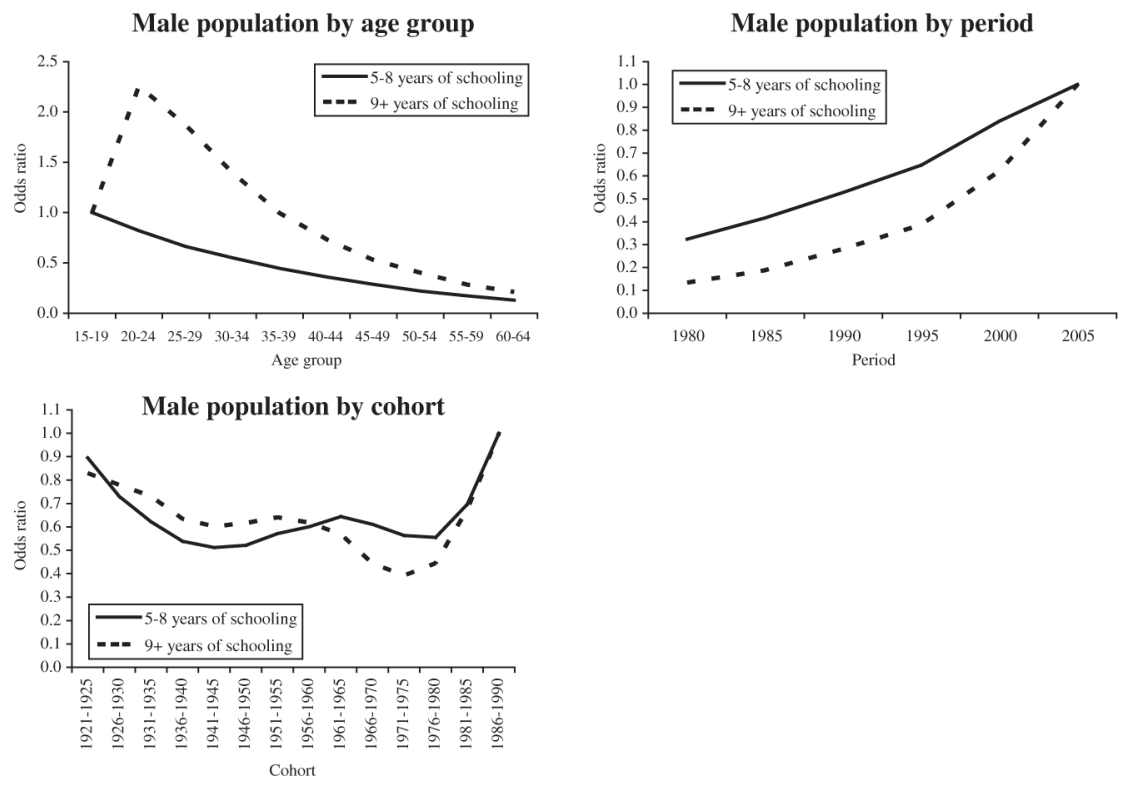

Figure 4.

Odds Ratios Estimated by Generalised Multinomial Logit Model to Explain the AgePeriod-Cohort Effect (APC Model) on Education Groups (Dependent Variable) for the Male Population, Brazil, 1980-2005.

Source: IBGE (2010e, 2010f, 2010g). (PNAD).

Note: Reference categories: 0-4 years of schooling; 15-19 age group; 2005 period; 19861990 cohort. 

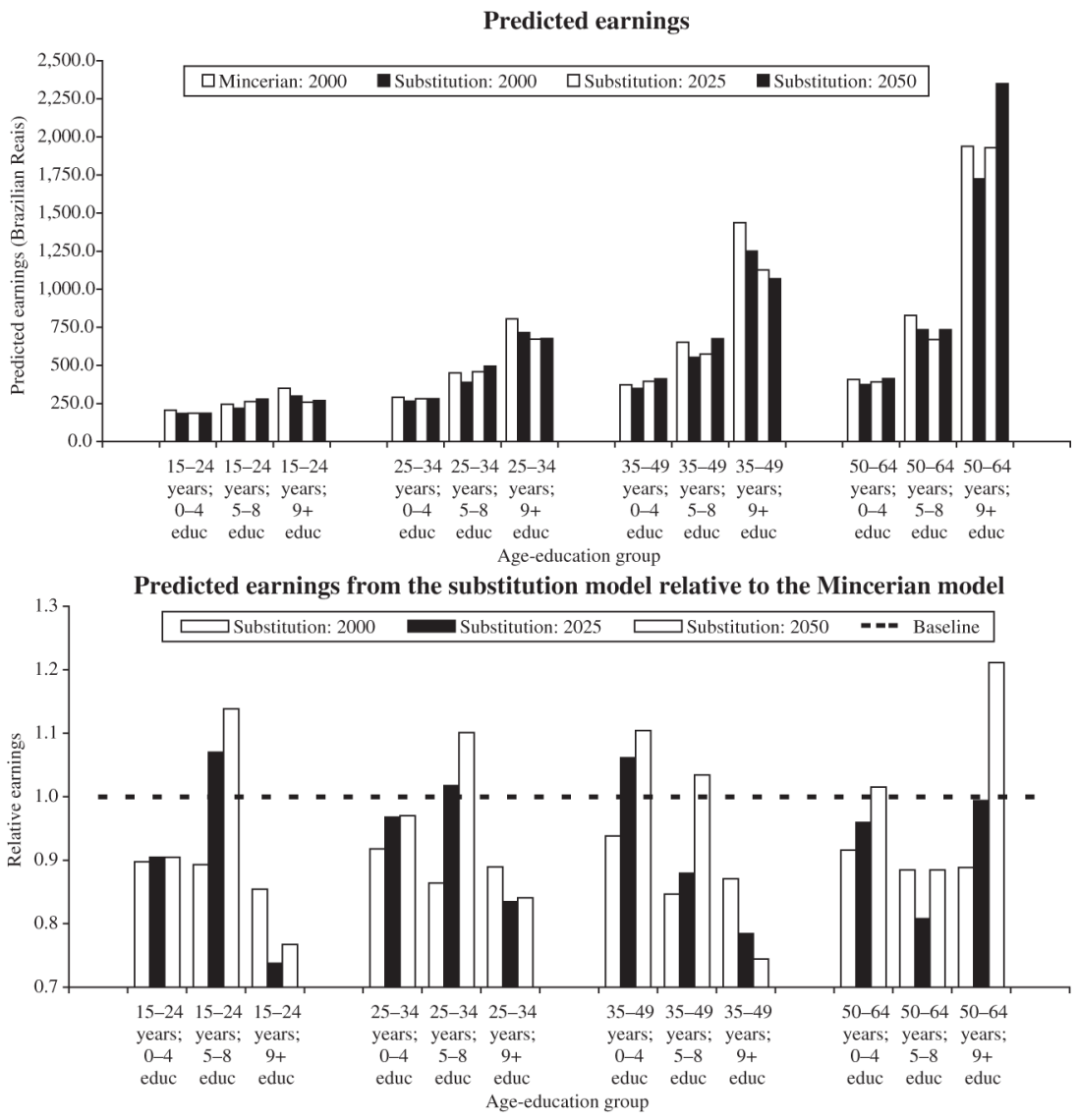

Figure 5.

Predicted Mean Real Monthly Earnings from Primary Occupation, ${ }^{\text {a }}$ Based on Projection

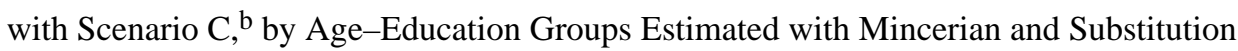
Models, Brazil, 2000-2050.

Source: IBGE (2010e, 2010f, 2010g, 2010h). (IBGE).

aNominal income was converted to base 1 in January 2002, taking into account changes in currency and inflation (Corseuil and Foguel 2002).

${ }^{\mathrm{b}}$ Scenario $\mathrm{C}$ considers the population ageing, as well as the trend of education growth of the last three points of cohort and period (1995, 2000 and 2005). 


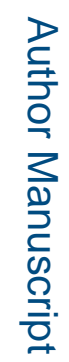

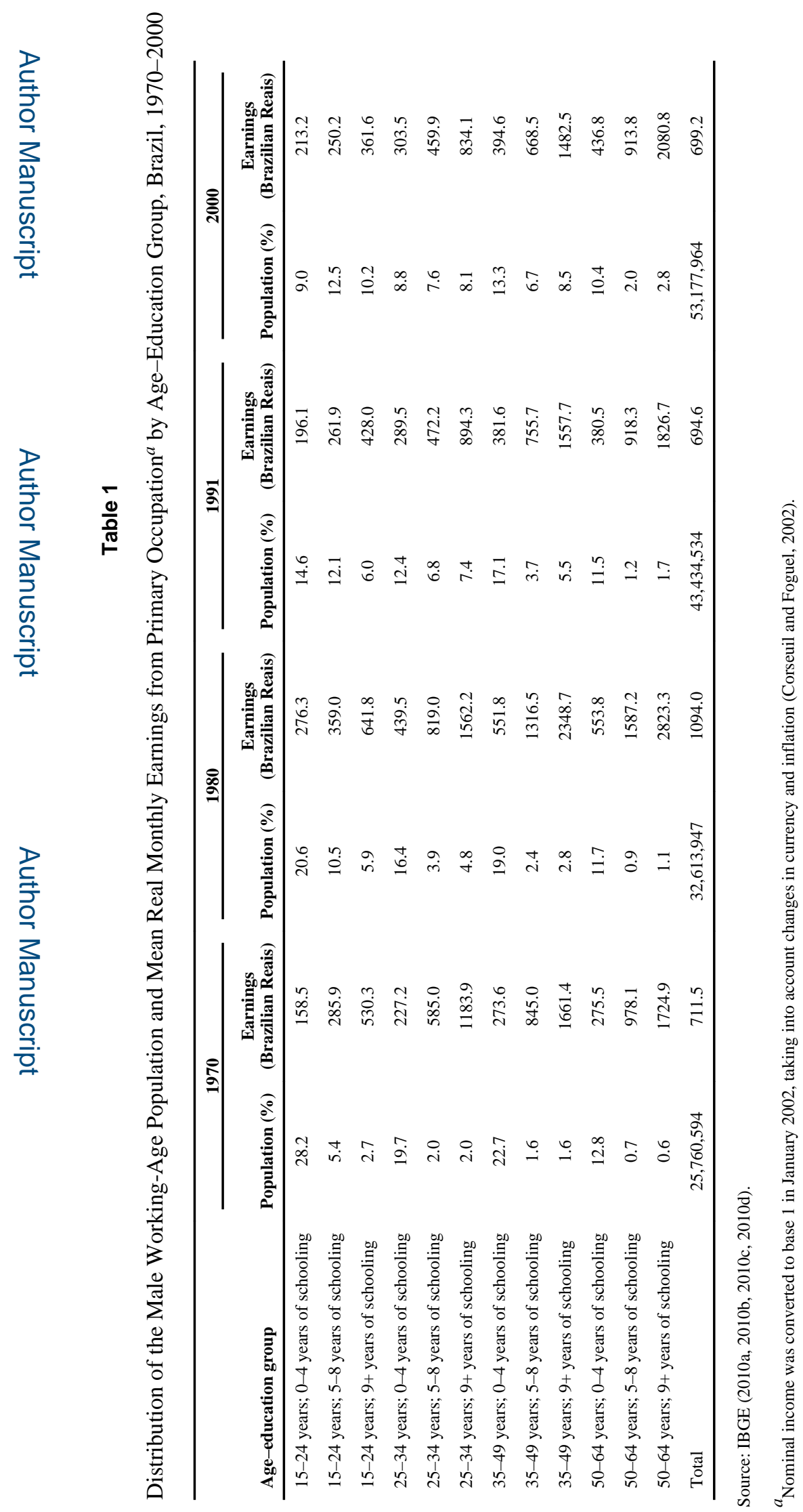

Bull Lat Am Res. Author manuscript; available in PMC 2015 July 01. 
Table 2

Percent Distribution of the Male Working-Age Population, Based on Projection with Scenario C, ${ }^{a}$ by AgeEducation Group, Brazil, 2005-2050

\begin{tabular}{lccc}
\hline Age-education group & $\mathbf{2 0 0 5}$ & $\mathbf{2 0 2 5}$ & $\mathbf{2 0 5 0}$ \\
\hline 15-24 years; 0-4 years of schooling & 4.6 & 0.2 & 0.0 \\
15-24 years; 5-8 years of schooling & 11.1 & 3.6 & 0.5 \\
15-24 years; 9+ years of schooling & 14.0 & 18.3 & 16.1 \\
25-34 years; 0-4 years of schooling & 6.8 & 0.4 & 0.0 \\
25-34 years; 5-8 years of schooling & 7.1 & 2.8 & 0.4 \\
25-34 years; 9+ years of schooling & 11.1 & 19.1 & 17.8 \\
35-49 years; 0-4 years of schooling & 11.2 & 3.3 & 0.1 \\
35-49 years; 5-8 years of schooling & 7.8 & 5.7 & 1.3 \\
35-49 years; 9+ years of schooling & 10.7 & 23.6 & 31.2 \\
50-64 years; 0-4 years of schooling & 8.9 & 5.9 & 0.5 \\
50-64 years; 5-8 years of schooling & 2.6 & 4.5 & 2.0 \\
50-64 years; 9+ years of schooling & 4.1 & 12.8 & 30.3 \\
Total & $59,506,167$ & $74,011,275$ & $68,754,692$ \\
\hline
\end{tabular}

Source: IBGE (2010e, 2010f, 2010g, 2010h). (PNAD); and Brazilian Population Projection by Sex and Age: 1980-2050 - Review 2008 (IBGE).

${ }^{a}$ Scenario C considers the population ageing, as well as the trend of education growth of the last three points of cohort and period (1995, 2000 and 2005). 